\title{
Long-Term Survival after CABG in Diabetics with Aggressive Risk Factor Management
}

\author{
Kendal Endicott1, Conor Hynes', Dominic Emerson1, Peter Kokkinos¹, Michael Greenberg2, \\ Gregory Trachiotis ${ }^{1,3}$ \\ ${ }^{1}$ Division of Cardiothoracic Surgery, Veterans Affairs Medical Center, Washington DC, USA \\ ${ }^{2}$ Division of Cardiology, Veterans Affairs Medical Center, Washington DC, USA \\ ${ }^{3}$ Division of Cardiothoracic Surgery, The George Washington University, Washington DC, USA \\ Email: gtrachiotis@mfa.gwu.edu
}

Received 20 September 2014; revised 20 October 2014; accepted 20 November 2014

Copyright @ 2014 by authors and Scientific Research Publishing Inc.

This work is licensed under the Creative Commons Attribution International License (CC BY).

http://creativecommons.org/licenses/by/4.0/

(c) (i) Open Access

\section{Abstract}

Objectives: Diabetes is a well-established risk factor for cardiovascular disease, and diabetics have a threefold increase in risk of death from cardiovascular disease compared to non-diabetics. Following coronary artery bypass grafting, tight glycemic control improves short-term outcomes, however limited data exist for long-term outcomes. Here we examine these outcomes in diabetics using aggressive risk factor management. Methods: A retrospective review of all patients undergoing coronary artery bypass between 1991 and 2000 at a single Veterans Affairs Medical Center was undertaken. 973 patients were included, 313 with diabetes and 660 without. Strict glucose control was maintained for all patients. Additional risk factor modification, including anti-platelets medications, statins, and beta blockers were also used. Survival analysis was performed. Results: The diabetic group was at higher risk, with age, BSA, and NYHA class all being greater ( $p<$ 0.05). The mean follow-up time was $6.7 \pm 3$ years. There were 28 deaths/1000 person-years for non-diabetics, and 48 deaths/1000 person-years for diabetics. Survival rates were significantly higher for non-diabetics $(72 \%$ versus $58 \%$ in the diabetic group, $p<0.001)$. Cox proportional hazard analysis demonstrated mortality risk was $57 \%$ higher for diabetic patients (hazard ratio = 1.57; CI: $1.19-2.09 ; p=0.002)$. The mortality risk in diabetics with and without prior MI was similar (HR = 0.83; CI: $0.54-1.28 ; p=0.40$ ). Conclusions: Diabetics undergoing coronary bypass have poorer long-term survival than non-diabetics despite perioperative glycemic control and risk factor modification. The long-term survival decrease in diabetics with history of MI is attenuated with surgical revascularization.

\section{Keywords}

Coronary Artery Bypass Graft, Diabetes, Mortality, Myocardial Infarction

How to cite this paper: Endicott, K., Hynes, C., Emerson, D., Kokkinos, P., Greenberg, M. and Trachiotis, G. (2014) LongTerm Survival after CABG in Diabetics with Aggressive Risk Factor Management. World Journal of Cardiovascular Surgery, 4, 217-222. http://dx.doi.org/10.4236/wjcs.2014.412031 


\section{Introduction}

Diabetes is a well-established risk factor for cardiovascular disease (CVD), and diabetics have a threefold increase in risk of death from CVD compared to the non-diabetic population [1] [2]. Current guidelines suggest that the isolated presence of diabetes confers an increased cardiac risk that is similar to prior myocardial infarction (MI), and should be treated as a "CHD equivalent" [3]. Endothelial and smooth muscle cell dysfunction as well as a predisposition to thrombosis has been linked to the hyperglycemic and insulin resistant state by multiple authors, and are seen as part of the driving force for this increased risk [4] [5]. To mitigate these factors, intensive glucose control ( $<20 \mathrm{mg} / \mathrm{dl})$ has been suggested, and is shown to reduce the risk of CVD [6] [7]; however, lasting effects of risk factor modification on subsequent cardiac events and mortality are mixed at best [2] [8] [9]. The addition of a prior history of advanced CVD (history of MI) within the diabetic population confers even greater risk of mortality; one that is significantly greater than the non-diabetic population after MI [10] [11].

It has been previously demonstrated that aggressive management of coronary disease in this group is essential, and that diabetic patients with extensive coronary disease have improved outcomes with CABG versus percutaneous therapies [12]-[15]. Aggressive risk factor management, including tight perioperative glycemic control has been shown to improve short-term outcomes in diabetics undergoing CABG [16]; however at present there are limited long-term data for the effect of aggressive risk factor modification on mortality following primary CABG in diabetics. In this study we seek to evaluate the effects of tight glycemic control and risk factor modification on mortality following CABG in the veteran diabetic population.

\section{Materials and Methods}

This study was approved February 14, 2012 following a review from the Institutional Review Board at the Washington, DC Veterans Affairs Medical Center, and a waiver of informed consent for participants was approved. All patients who underwent CABG between 1991-2000 at a single site were evaluated. In total, 973 patients were identified. A retrospective review of prospectively collected data from our pre-existing in-house database was undertaken. From this initial cohort of 973, 313 were diabetic (DM) and 660 were not (NDM). During the period studied a standardized protocol for management of diabetic patients undergoing CABG was utilized. All patients had blood glucose evaluated preoperatively and postoperatively. If preoperative glucose was found to be $>250 \mathrm{mg} / \mathrm{dl}$ at any point, insulin therapy was initiated, regardless of prior diabetic status, to achieve glucose levels $<200 \mathrm{mg} / \mathrm{dl}$, and the patient was placed on serial glucose monitoring to maintain tight control of glucose levels. Postoperatively all patients requiring preoperative glucose control were maintained $<200 \mathrm{mg} / \mathrm{dl}$ for 24 - 48 hours using a sliding scale insulin, or insulin drip, where appropriate. Additionally, all patients not requiring preoperative glucose control were also monitored to ensure levels stayed $<200 \mathrm{mg} / \mathrm{dl}$, and therapy was initiated if this did not occur. Following the immediate postoperative period, all diabetics were then transitioned to their preoperative standard regimen, and if glucose management was difficult to control, a specialized diabetic endocrinologist was consulted and therapy was adjusted accordingly.

Diabetic patients were discharged with medication (oral or insulin) in $87 \%$ of cases. During the study period the routine use of risk factor modifying medication evolved to mirror the changing best clinical evidence. In particular, the use of statins and beta blockers increased as evidence for their efficacy grew. At the end of the study (the year 2000), antiplatelet medications were used in more than $83 \%$ of patients, statins were used in $90 \%$, beta-blocker usage was present in 90\%, and an angiotensin converting enzyme (ACE) inhibitor or angiotensin receptor blocker (ARB) was used in $83 \%(\mathrm{EF}<40 \%)$.

Following data collection, a comparison of adjusted and unadjusted data was undertaken. Continuous variables are presented as mean values \pm SD and categorical variables as relative frequencies (\%). Preoperative characteristics, intraoperative variables, and postoperative complications between diabetics and non-diabetics were compared using one-way analysis of variance (ANOVA) to evaluate mean differences of normally distributed continuous variables, and a $\chi^{2}$ analysis was used to evaluate associations between categorical variables. Follow-up time is presented as median and mean \pm SD. Mortality rate was calculated as the ratio of deaths by the person-years of observation. Cox proportional hazards models were applied to assess all cause mortality diabetics and non-diabetics and the risk of an MI in diabetic and non-diabetic patients; models were adjusted for age, NYHA class III-IV, CAD risk and smoking status. All statistical analyses were performed using SPSS software version 21.0 (SPSS Inc., Chicago, IL, USA) using our in-house statistician. 


\section{Results}

Patient characteristics and clinical demographics are summarized in Table 1.

Both groups were predominately male, and those with DM tended to be older (64 \pm 9 versus $62 \pm 10$, p = 0.022 ) and have a larger BSA (2.0 versus 1.97, $\mathrm{p} \leq 0.001)$. Left ventricular end diastolic pressures (LVEDP) were higher in the diabetic group (17.6 \pm 8 versus $16.2 \pm 7, \mathrm{p}=0.014)$ as were pulmonary arterial systolic pressures (PASP) $(31.7 \pm 9$ versus $35.8 \pm 12, \mathrm{p}=0.006)$, both risk factors for poor outcomes. Comparison of mean aortic systolic pressure (AoSP), a marker for hypertension, was also significantly higher in the diabetic group (140 \pm 27 versus $134 \pm 27, \mathrm{p}=0.004)$. Rates of prior myocardial infarction and CCA III-IV class were similar, however, the diabetic group had a higher rate of heart failure based on NYHA classification (class III-IV) $(47.6 \%$ versus $39 \%, \mathrm{p}<0.001)$. Additionally, CAD risk score $>3$ was more common in the diabetic group (73.8\% versus 67.6\%, $\mathrm{p}=0.015$ ). Operative data was found to be similar between groups in terms of the number of grafts used, use of the IMA grafting, percentage of Off-Pump Coronary Artery Bypass procedures (OPCAB), and rate of single bypass graft (Table 2).

A multivariable analysis by Cox proportional hazard analysis examining the influence of preoperative risk factors on outcomes demonstrated that age (HR $=1.04, \mathrm{CI}: 1.03-1.06, \mathrm{p}<0.001)$, NYHA class III-IV (HR = 1.80, CI: $1.02-3.18, p=0.04)$ and low EF (HR = 0.68, CI: $0.47-0.99, p=0.04$ ) were independent predictors of mortality for the entire cohort (DM and NDM).

Rates of postoperative morbidity were generally similar between groups, with no statistical difference observed in the rates of prolonged ventilation $(p=0.56)$, stroke $(p=0.3)$, perioperative MI $(p=0.97)$, or mediastinitis $(p=0.3)$ (Table 3$)$.

Table 1. Demographics.

\begin{tabular}{cccc}
\hline & NDM $(\mathrm{n}=660)$ & DM $(\mathrm{n}=313)$ & $\mathbf{p}=\mathbf{0 . 0 2 2}$ \\
Age & $62 \pm 10$ & $64 \pm 9$ & $\mathbf{p}<\mathbf{0 . 0 0 1}$ \\
BSA & $1.97 \pm 0.2$ & $2 \pm 0.2$ & $\mathbf{p}=\mathbf{0 . 0 1 4}$ \\
LVEDP & $16.2 \pm 7$ & $17.6 \pm 8$ & $\mathbf{p}=\mathbf{0 . 0 0 4}$ \\
AOSP & $134 \pm 27$ & $140 \pm 27$ & $\mathbf{p}=\mathbf{0 . 0 0 6}$ \\
PASP & $31.7 \pm 9$ & $35.8 \pm 12$ & $\mathrm{p}=0.42$ \\
Prior MI & $53.9 \%(356)$ & $56.6 \%(177)$ & $\mathrm{p}=0.31$ \\
CCA III-IV & $91.4 \%(603)$ & $88.9 \%(278)$ & $\mathbf{p}<\mathbf{0 . 0 0 1}$ \\
NYHA III-IV & $39 \%(257)$ & $47.6 \%(149)$ & \\
\hline
\end{tabular}

Table 2. Operative data.

\begin{tabular}{cccc}
\hline & NDM (n) & DM (n) & \\
\hline CAD $>3$ & $67.6 \%(446)$ & $73.8 \%(231)$ & $\mathbf{p}=\mathbf{0 . 0 1 5}$ \\
CABG $\times 1$ & $14.2 \%(94)$ & $8.0 \%(25)$ & $\mathrm{p}=0.06$ \\
OPCAB & $14.7 \%(97)$ & $15.8 \%(49)$ & $\mathrm{p}=0.07$ \\
Number of grafts & 2.47 & 2.52 & $\mathrm{p}=0.052$ \\
IMA & $87.7 \%(579)$ & $89.8 \%(281)$ & $\mathrm{p}=0.34$ \\
\hline
\end{tabular}

Table 3. Hospital events.

\begin{tabular}{cccc}
\hline & NDM (n) & DM (n) & p = 0.56 \\
\hline Vent $48 \mathrm{hr}$ & $4.8 \%(32)$ & $5.8 \%(18)$ & $\mathrm{p}=0.3$ \\
Stroke & $1.1 \%(7)$ & $1.9 \%(6)$ & $\mathrm{p}=0.97$ \\
Periop MI & $4.9 \%(32)$ & $2.4 \%(8)$ & $\mathrm{p}=0.3$ \\
Mediastinitis & $1.8 \%(12)$ & $2.9 \%(9)$ & $\mathrm{p}=0.11$ \\
Death & $2.3 \%(15)$ & $3.8 \%(12)$ & \\
\hline
\end{tabular}


Operative mortality was generally low, at 3.9\% in DM versus 2.2\% in the NDM group (Table 3, p = 0.11). For long-term survival, the mean follow-up time was $6.7 \pm 3$ years (6762 person-years of observation). During this period there were 229 deaths (34/1000 person-years) in total, with 137 (28 deaths/1000 person-years) for non-diabetics, and 92 (48 deaths/1000 person-years) for diabetics. Unadjusted mortality rates were significantly lower for the NDM group (72\% versus 58\% in the DM group ( $<<0.001)$ ). Cox proportional hazard analysis adjusted for age, NYHA class, CAD risk score and smoking status demonstrated that the mortality risk for diabetic patients was 57\% higher when compared to non-diabetics (HR = 1.57, CI: 1.19 - 2.09, p = 0.002, Figure 1).

Regarding the subset of patients with a prior history of MI, the mortality risk in diabetic patients with prior MI was similar to those who had never had an MI (Hazard Ratio = 0.83, CI: $0.54-1.28$, p = 0.40, Figure 2), in-

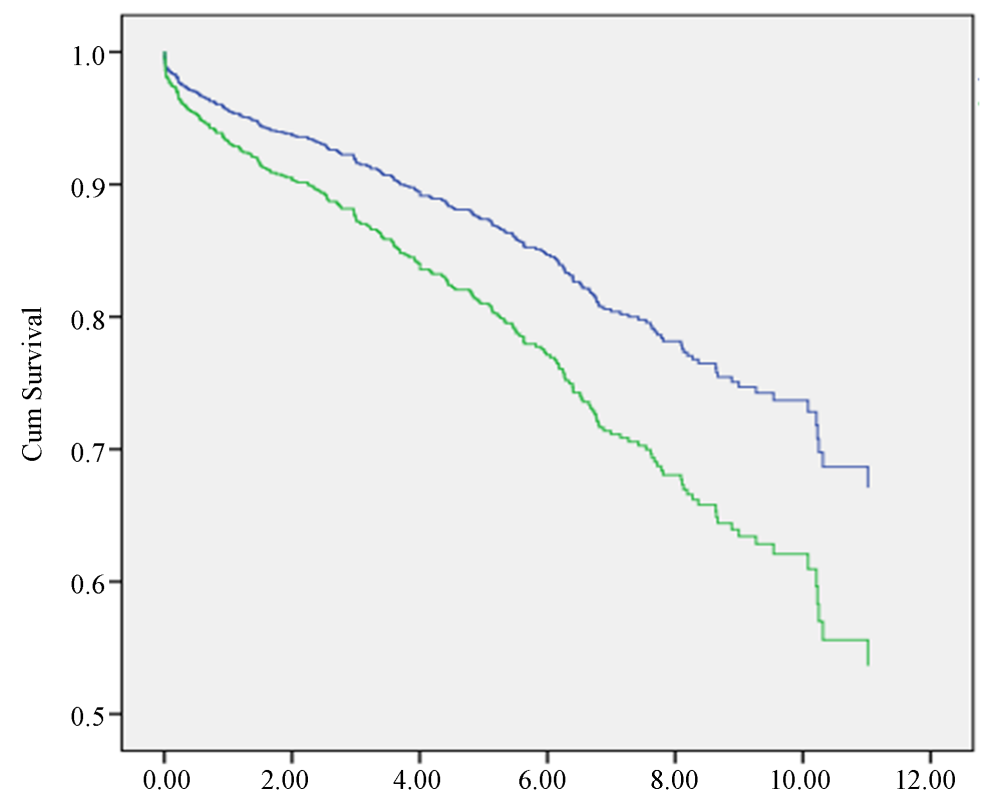

Figure 1. Survival curves for diabetic and non-diabetic patients.

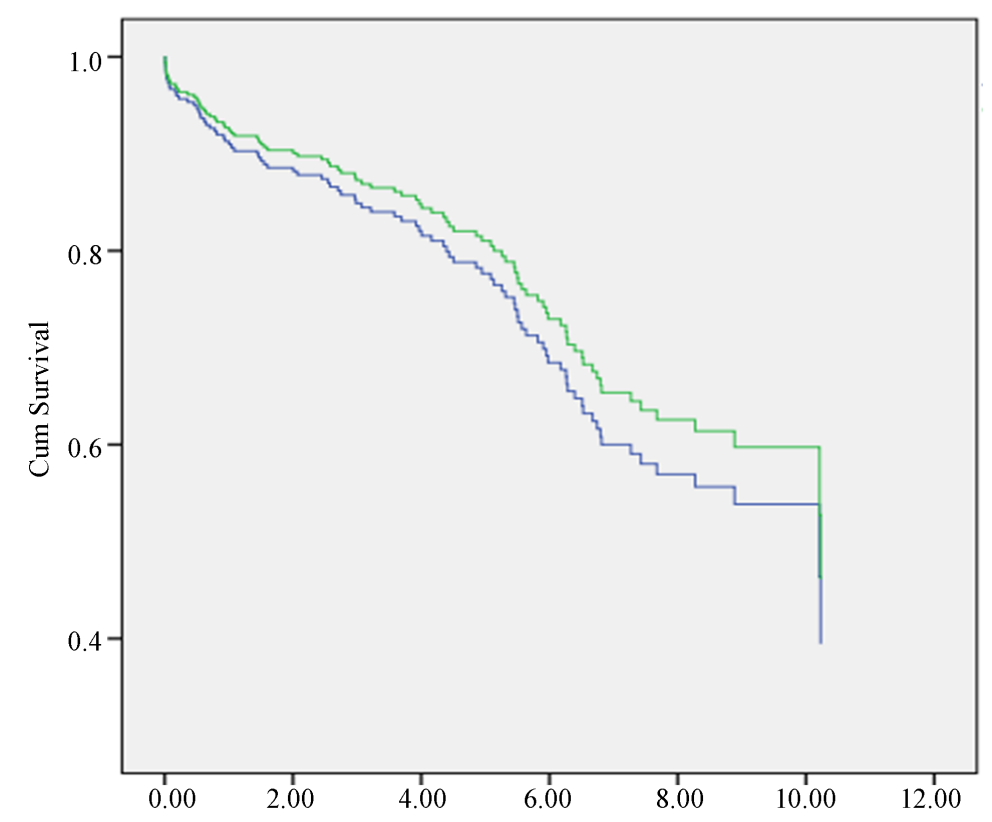

Figure 2. Survival curves for diabetic patients with and without prior myocardial infarction. 
dicating an attenuation the increased risk conferred with a history of prior MI demonstrated by previous authors [17].

\section{Discussion}

The increased risk of coronary artery disease in the diabetic population is well established. In addition to this higher rate, diabetic patients who present for surgery tend to have a higher risk profile as compared to non-diabetic patients [18]. This trend was observed in our cohort, with diabetic patients on average having higher LVEDP, AOSP, and PASP values, as well as higher rates of NYHA Class III-IV heart failure, indicating a generally higher risk population [18]-[20]. Previous work evaluating the effects of diabetes on the CABG patient population has demonstrated that this higher risk profile leads to an increased number of immediate post-operative complications [18]; however, in our study there was no difference in the rate of morbidity events between the NDM and DM groups. We hypothesize that this is in part attributable to stringent glycemic goals post-operatively and medical management of coronary risk factors within our cohorts, something not present to the same degree in previous studies.

Our data indicates that all-cause long term survival is worse in the diabetic population post-CABG, as anticipated. The factors predisposing this cohort to a survival difference seem to stem from the unfavorable preoperative characteristics mentioned above, rather than from intraoperative differences, as these data were similar in our study despite a higher burden of coronary disease within the DM cohort. Of note, the percentage of individuals in both cohorts receiving IMA grafting was high, but this did not appear to influence the burden of disease for either the NDM or DM cohorts.

AoSP (a marker of the presence of hypertension) and PASP (a marker of the presence of pulmonary hypertension) were strong pre-operative variables that statistically influenced survival in the DM group but not the NDM group. We believe that ischemic disease superimposed on some degree of underlying cardiomyopathy quantified by AoSP and PASP contributed to long term poorer outcomes in our diabetic population. It is believed that the negative effects of this underlying cardiomyopathy effected the DM group more due to a combination of increased severity of underlying cardiac dysfunction (AoSP and PASP were higher in the DM group), as well as the relative burden imparted by being diabetic.

A history of prior MI in diabetic patients has been previously demonstrated to significantly shorten all-cause survival, with 10-year all-cause survival of patients with DM and prior MI being as low as 33\% [17]. This phenomena, as well as a large body of work demonstrating that the presence of isolated DM confers a cardiac risk at least similar to that of prior MI, has led to the current recommendations that diabetes should be treated as a "CHD equivalent" by the American Heart Association [3]. It is therefore significant that, within this study population, the long-term survival for patients with DM and prior MI appears no worse than survival for patients with DM and no history of MI. This apparent attenuation of the additional risk conferred by a history of MI indicates that diabetic patients with a history of advanced coronary disease benefit strongly from aggressive revascularization. Furthermore, with prior data indicating that CABG is the preferred method of intervention (over PTCA) in the diabetic population [13]-[15], this aggressive revascularization is likely best preformed in a surgical setting.

\section{Conclusion}

In summary, patients with diabetes undergoing CABG have poorer long-term survival than non-diabetics despite perioperative glycemic control and risk factor modification. However, the effect of prior MI on long-term survival in diabetics is attenuated with surgical revascularization. It remains to be defined whether long-term management of glycemic control and risk factor modification can improve overall survival among diabetics after CABG.

\section{References}

[1] Vaccaro, O., Eberly, L.E., et al. (2004) Impact of Diabetes and Previous Myocardial Infarction on Long-Term Survival: 25 Year Mortality Follow-Up of Primary Screenees of the Multiple Risk Factor Intervention Trial. Archives of Internal Medicine, 164, 1438-1443. http://dx.doi.org/10.1001/archinte.164.13.1438

[2] Skyler, J.S., Bergenstal, R., et al. (2008) Intensive Glycemic Control and the Prevention of Cardiovascular Events: Implications of the Accord, Advnace, and VA Diabetes Trials. Journal of the American College of Cardiology, 53, 298- 
304. http://dx.doi.org/10.1016/j.jacc.2008.10.008

[3] Smith Jr., S.C., Greenland, P. and Grundy, S.M. (2000) Prevention Conference V: Beyond Secondary Prevention: Identifying the High-Risk Patient for Primary Prevention: Executive Summary. Circulation, 101, 111-116. http://dx.doi.org/10.1161/01.CIR.101.1.111

[4] Creager, M.A. and Lüscher, T.F. (2003) Diabetes and Vascular Disease: Pathophysiology, Clinical Consequences, and Medical Therapy: Part I. Circulation, 108, 1527-1532. http://dx.doi.org/10.1161/01.CIR.0000091257.27563.32

[5] Beckman, J.A., Creager, M.A. and Libby, P. (2002) Diabetes and Atherosclerosis. JAMA, 287, 2570-2581.

[6] NICE-SUGAR Study Investigators, et al. (2009) Intensive versus Conventional Glucose Control in Critically Ill Patients. The New England Journal of Medicine, 360, 1283-97. http://dx.doi.org/10.1056/NEJMoa0810625

[7] Juvenile Diabetes Research Foundation Continuous Clucose Monitoring Study Group, et al. (2008) Continuous Glucose Monitoring and Intensive Treatment of Type 1 Diabetes. The New England Journal of Medicine, 359, 1464-1476. http://dx.doi.org/10.1056/NEJMoa0805017

[8] Holman, R.R., Paul, S.K., et al. (2008) Long-Term Follow-Up after Tight Control of Blood Pressure in Type 2 Diabetes. The New England Journal of Medicine, 359, 1565-1576. http://dx.doi.org/10.1056/NEJMoa0806359

[9] Holman, R.R., Paul, S.K., et al. (2008) 10-Year Follow-Up of Intensive Glucose Control in Type 2 Diabetics. The New England Journal of Medicine, 359, 1577-1589. http://dx.doi.org/10.1056/NEJMoa0806470

[10] Jacoby, R.M. and Nesto, R.W. (1992) Acute Myocardial Infarction in the Diabetic Patient: Pathophysiology, Clinical Course and Prognosis. Journal of the American College of Cardiology, 20, 736-744. http://dx.doi.org/10.1016/0735-1097(92)90033-J

[11] Cho, E., Rimm, E.B., et al. (2002) The Impact of Diabetes Mellitus and Prior Myocardial Infarction on Mortality from All Causes and from Coronary Heart Disease in Men. Journal of the American College of Cardiology, 40, 954-960. http://dx.doi.org/10.1016/S0735-1097(02)02044-2

[12] BARI 2D Study Group, et al. (2009) A Randomized Trial of Therapies for Type 2 Diabetes and Coronary Artery Disease. The New England Journal of Medicine, 360, 2503-2515. http://dx.doi.org/10.1056/NEJMoa0805796

[13] Chaitman, B.R. and Hardison, R.M. (2009) The Bypass Angioplasty Revascularization Investigation 2 Diabetes Randomized Trial of Different Treatment Strategies in Type 2 Diabetes Mellitus with Stable Ischemic Heart Disease. Circulation, 120, 2529-2540. http://dx.doi.org/10.1161/CIRCULATIONAHA.109.913111

[14] Mack, M.J., Banning, A.P., et al. (2011) Bypass versus Drug-Eluting Stents at Three Years in Syntax Patients With Diabetes Mellitus or Metabolic Syndrome. The Annals of Thoracic Surgery, 92, 2140-2146. http://dx.doi.org/10.1016/j.athoracsur.2011.06.028

[15] BARI Study Group, et al. (1997) Influence of Diabetes on 5-Year Mortality and Morbidity in a Randomized Trial Comparing CABG and PTCA in Patients With Multivessel Disease: The Bypass Angioplasty Revascularization Investigation (BARI). Circulation, 96, 1761-1769. http://dx.doi.org/10.1161/01.CIR.96.6.1761

[16] Lazar, H.L., Chipkin, S.R., et al. (2004) Tight Glycemic Control in Diabetic Coronary Artery Bypass Graft Patients Improves Perioperative Outcomes and Decreases Recurrent Ischemic Events. Circulation, 109, 1497-1502. http://dx.doi.org/10.1161/01.CIR.0000121747.71054.79

[17] Wannamethee, S.G., Shaper, A.G. and Lennon, L. (2004) Cardiovascular Disease Incidence and Mortality in Older Men with Diabetes and in Men with Coronary Heart Disease. Heart, 90, 1398-1403. http://dx.doi.org/10.1136/hrt.2003.026104

[18] Thourani, V.H., Weintraub, W.S., et al. (1999) Influence of Diabetes Mellitus on Early and Late Outcome after Coronary Artery Bypass Grafting. The Annals of Thoracic Surgery, 67, 1045-1052.

[19] Salem, R., Denault, A.Y., Couture, P., et al. (2006) Left Ventricular End-Diastolic Pressure Is a Predictor of Mortality in Cardiac Surgery Independently of Left Ventricular Ejection Fraction. British Journal of Anaesthesia, 97, 292-297. http://dx.doi.org/10.1093/bja/ael140

[20] Nashef, S.A., Roques, F., Sharples, L.D., Nilsson, J., Smith, C., Goldstone, A.R. and Lockowandt, U. (2012) EuroSCORE II. European Journal Cardio-Thoracic Surgery, 41, 734-745. http://dx.doi.org/10.1093/ejcts/ezs043 
Scientific Research Publishing (SCIRP) is one of the largest Open Access journal publishers. It is currently publishing more than 200 open access, online, peer-reviewed journals covering a wide range of academic disciplines. SCIRP serves the worldwide academic communities and contributes to the progress and application of science with its publication.

Other selected journals from SCIRP are listed as below. Submit your manuscript to us via either submit@scirp.org or Online Submission Portal.
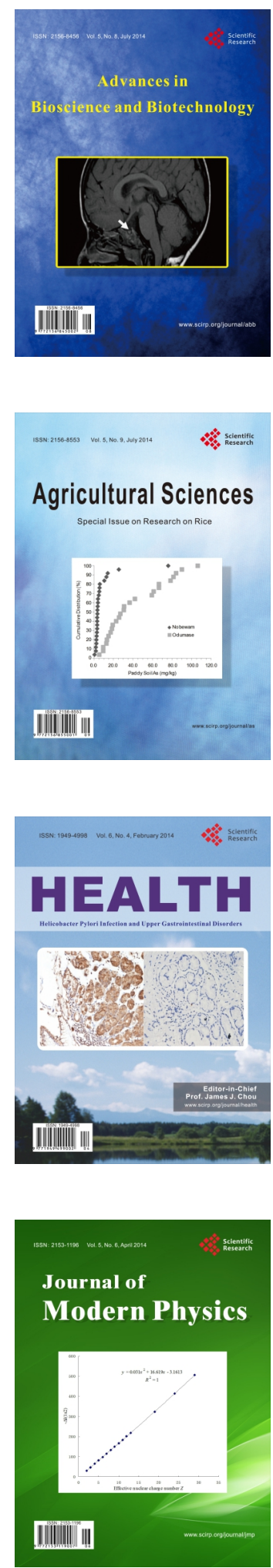
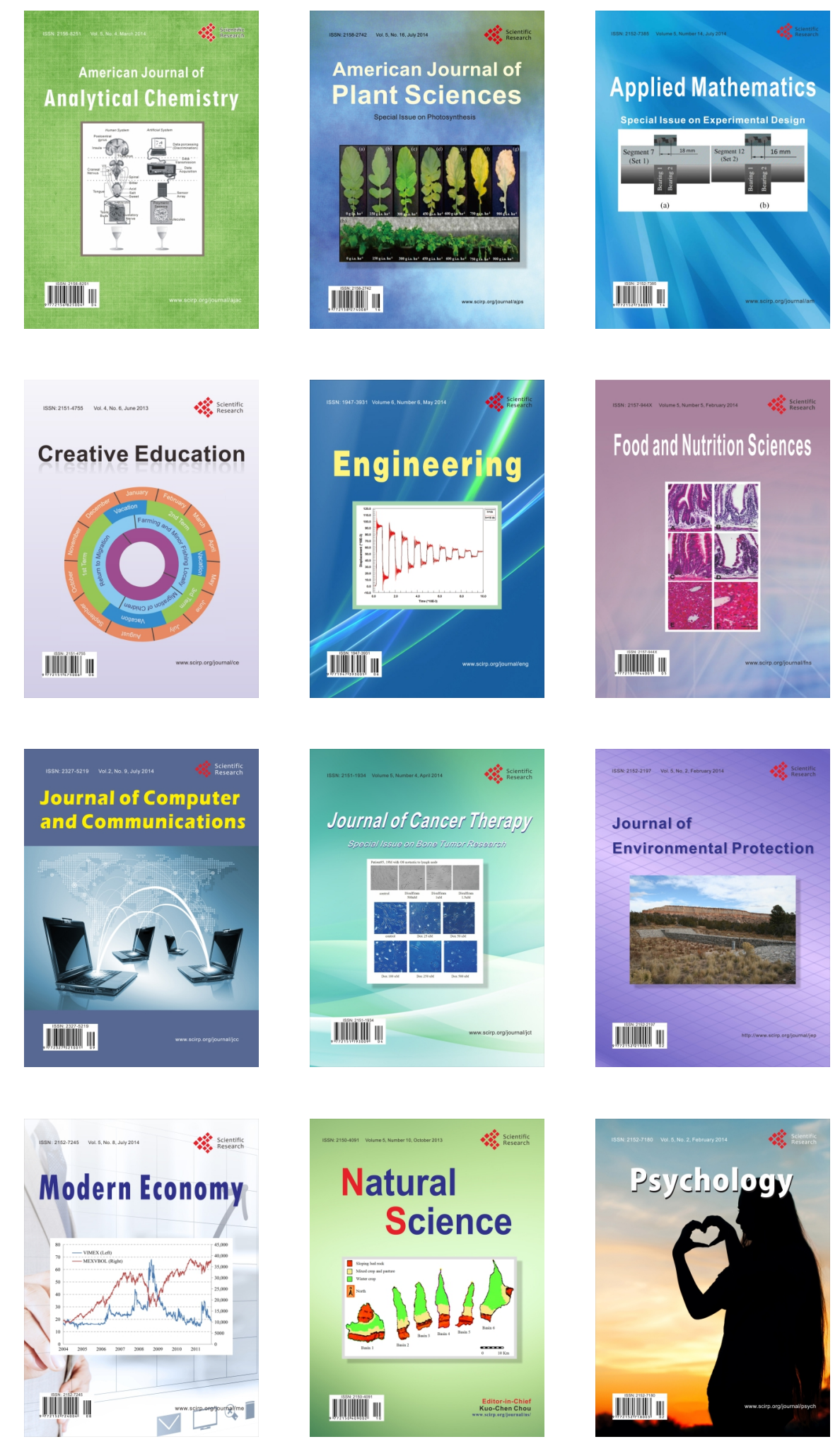